\title{
A CASE OF VON RECKLINGHAUSEN'S DISEASE WITH DIFFUSE NEUROFIBROMATOSIS OF THE CHOROID*
}

\author{
BY \\ S. ROBSON \\ SURGEON TO THE SIR JOHN PRIESTMAN, SUNDERLAND \\ AND DURHAM COUNTY EYE INFIRMARY \\ and \\ W. BLACKWOOD \\ FROM THE SCOTTISH MENTAL HOSPITAL LABORATORY, AND \\ THE DEPARTMENTS OF PATHOLOGY OF THE ROYAL \\ INFIRMARY AND UNIVERSITY, EDINBURGH \\ and \\ H. A. COOKSON \\ HON. PATHOLOGIST, THE ROYAL INFIRMARY, SUNDERLAND
}

\section{Introduction}

IN Von Recklinghausen's disease, the occurrence of a neurofibroma of the short ciliary nerves is an uncommon occurrence and for this reason, the case is presented for record.

Further, later in the account, special reference is made to the " ovoid bodies " described by Masson and their nature commented upon.

\section{Clinical Notes}

On September 30, 1939, W.B., a boy aged 18 years, came to the Durham County and Sunderland Eye Infirmary with a four years' history of an enlarged and thickened upper right lid; it was pendulous and overlapped the lower lid for $\frac{3}{4}$ of an inch. (See Fig. A.) Movement of the lid was practically nil.

The palpebral conjunctiva was velvety and there was considerable mucous discharge. On palpation some worm-like swellings could be felt under the skin of the upper lid, and there were similar but smaller ones running in a diverging manner above each eyebrow.

On the front of the right side of the neck (see Fig. B) there were 2 or 3 small movable isolated swellings under the skin. Further examination showed more small swellings of a similar character on the abdomen in the course of the intercostal nerves, and others in the left groin and front of the left shoulder. (See Fig. C.)

There was a large café-au-lait patch on the left buttock, and there were smaller ones on the front of the abdomen and on the back.

\footnotetext{
* Received for publication, June 11, 1941.
} 


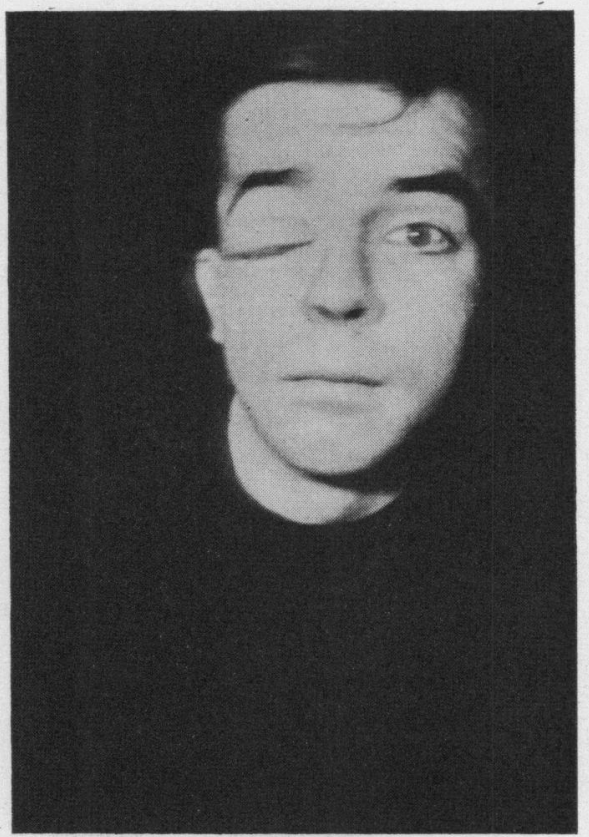

FIG. A.

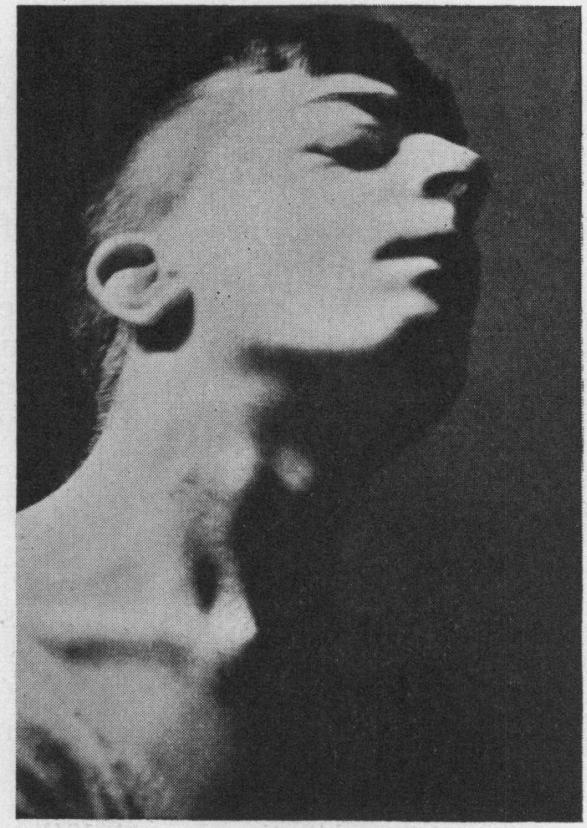

FIG. B. 
Right eye. The anterior chamber was normal, and the cornea and lens were clear. The pupil was pear-shaped and eccentric in an up and out position; it was larger than the left, and the reaction to light was very sluggish.

There was a very large detachment of the retina with a slight fundus reflex on the nasal side, and transillumination showed dullness on the temporal side.

The intra-ocular pressure was $22 \mathrm{~mm}$., and the vision was reduced to perception of light in the temporal region. There was no pulsation of the eyeball.

Sections of the lid and a swelling in the neck were taken for biopsy, and sent to Dr. H. A. Cookson, Hon. Pathologist. An $\mathrm{X}$-ray film showed no abnormality in the optic foramina.

By June, 1940, the detachment of the retina had slowly increased in size, and could be easily seen through the pupil by oblique illumination. On the surface of the detachment was a new formation of vessels apparently arising from the nasal side.

On June 4 , the eye was enucleated and sent to Dr. H. A. Cookson. After removal of the eye no tumour formation could be felt in the orbit.

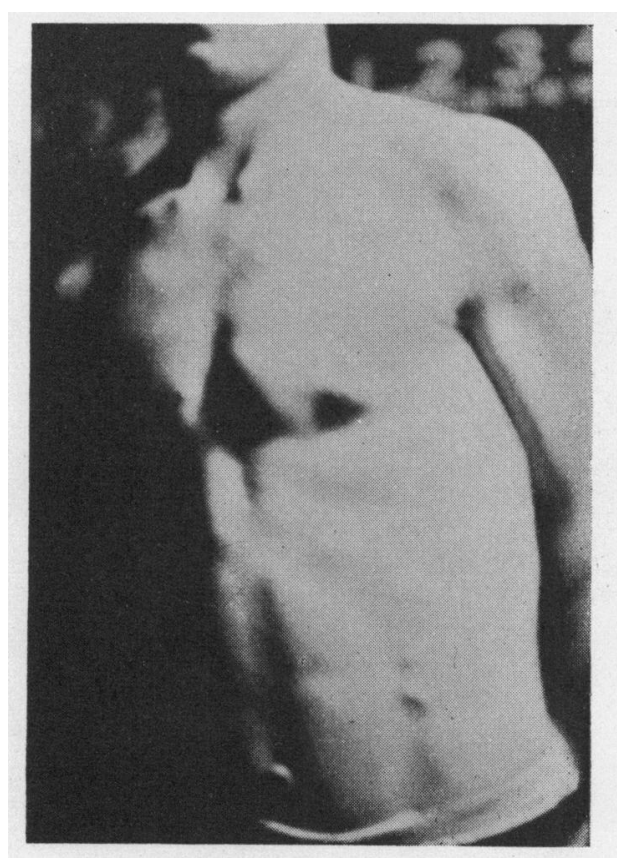

FIG. C. 
Incidentally, he had an operation for ruptured gastric ulcer in January, 1940. Otherwise he is healthy, with no mental symptoms.

An interesting feature of the case is that within the last few months the back and the abdomen have become completely covered with innumerable small café-au-lait spots. (See Fig. C.)

As his parents were worried about the deformity of the upper lid, three operations have been performed on it in order to improve his appearance.

\section{Examination of Specimens}

1. Small biopsy from right upper eyelid (embedded in paraffin).

Sections were stained haematein eosin, Van Gieson for connective tissue and Loyez for myelin sheaths.

Examination showed that the specimen consisted almost entirely of collagen fibres. In the section stained (Loyez) there were two fibrils which were suggestive of myelinated nerves.

Having regard to the clinical findings the appearances were compatible with neurofibromatosis.

2. Biopsy from neck (formol fixed).

The specimen consisted of an elongated mass, approximately $19 \mathrm{~mm}$. long and $7 \mathrm{~mm}$. in transverse diameter, of firm pale gelatinous tissue.

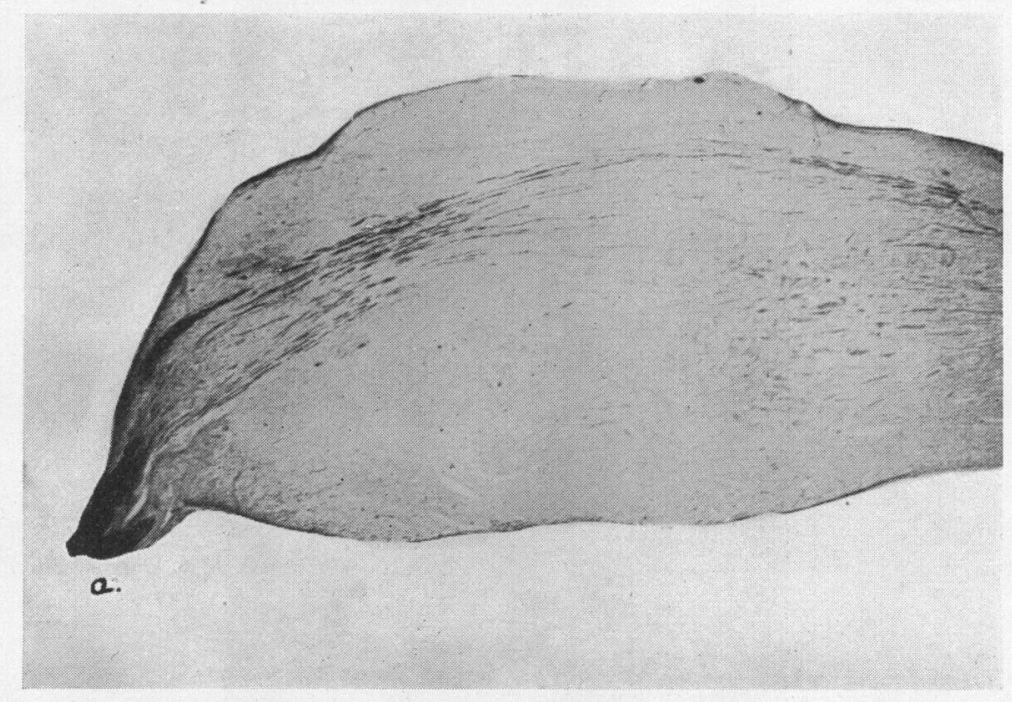

Fig. 1.

Biopsy from neck. $a=$ entering whole nerve. Spielmeyer myelin sheath stain. $\times 6$ 


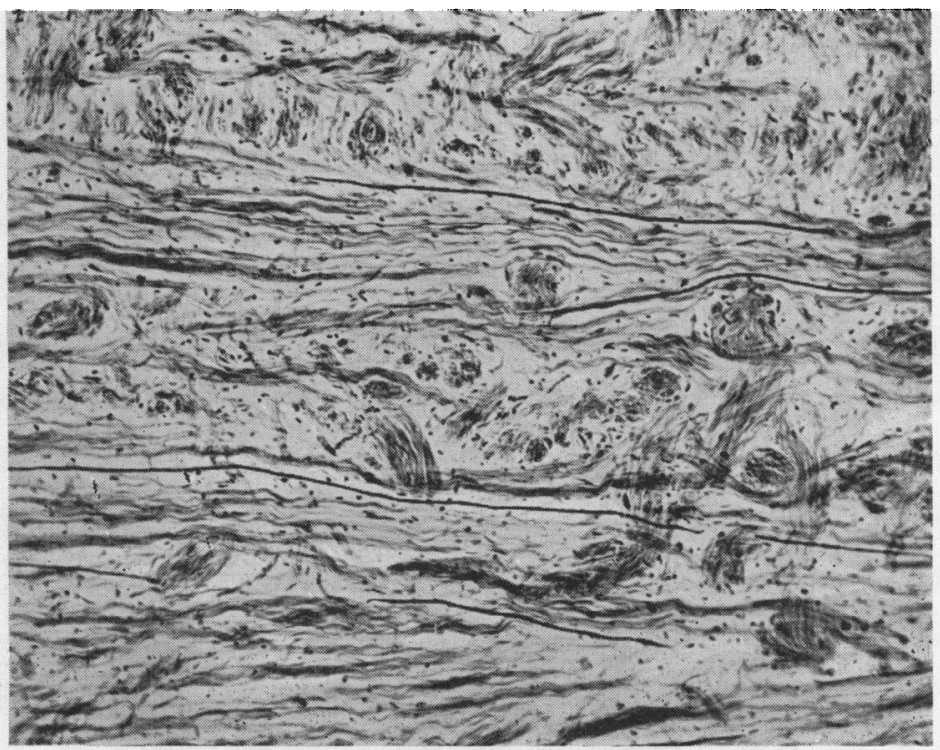

FIG. 2.

Biopsy from neck. Neurofibrils passing through connective tissue network. Hortega neurofibril stain. $\times 110$.

It was bisected longitudinally and frozen sections were stained for axis cylinders (Hortega) and myelin sheaths (Spielmeyer counterstained Van Gieson).

Examination showed that one pole of the nodule consisted of a normal, compact myelinated nerve (a, Fig. 1$)$ and from this nerve the fibres entered the nodule, fanning out and passing in smooth curves through a richly cellular and well vascularized mass of connective tissue fibrils (Fig. 2).

The appearances were those of neurofibromatosis.

\section{Portion of eye (formol fixed).}

The specimen received consisted of the posterior half of the eye with an attached portion of optic nerve.

The optic nerve appeared normal. The retina was detached except around the margins of the optic disc. The sclera appeared normal. The choroid was diffusely thickened and dark in colour. To the temporal side of the optic disc, mostly within the substance of the choroid but partly on the extra-ocular surface of the sclera, was a $4 \mathrm{~mm}$. diameter nodule of pale, firm, homogeneous tissue.

The specimen was divided in the para-sagittal plane. One portion, containing the optic nerve head was carried through paraffin and sections stained haematem eosin, Masson trichrome 
(with light green as counterstain) and Azan. The other portion, containing the main body of the tumour, was first cut frozen and stained for myelin sheaths (Spielmeyer) and neurofibrils (Hortega) and then the remainder was embedded in paraffin and stained as before.

Microscopical examination showed that the optic nerve, optic disc, retina and sclera showed no particular abnormality. The pathological change was in the choroid and the short ciliary nerves.

The choroid was generally thickened (Fig. 3), with a focal accentuation of the thickening in the area of pale swelling (Fig. 4).

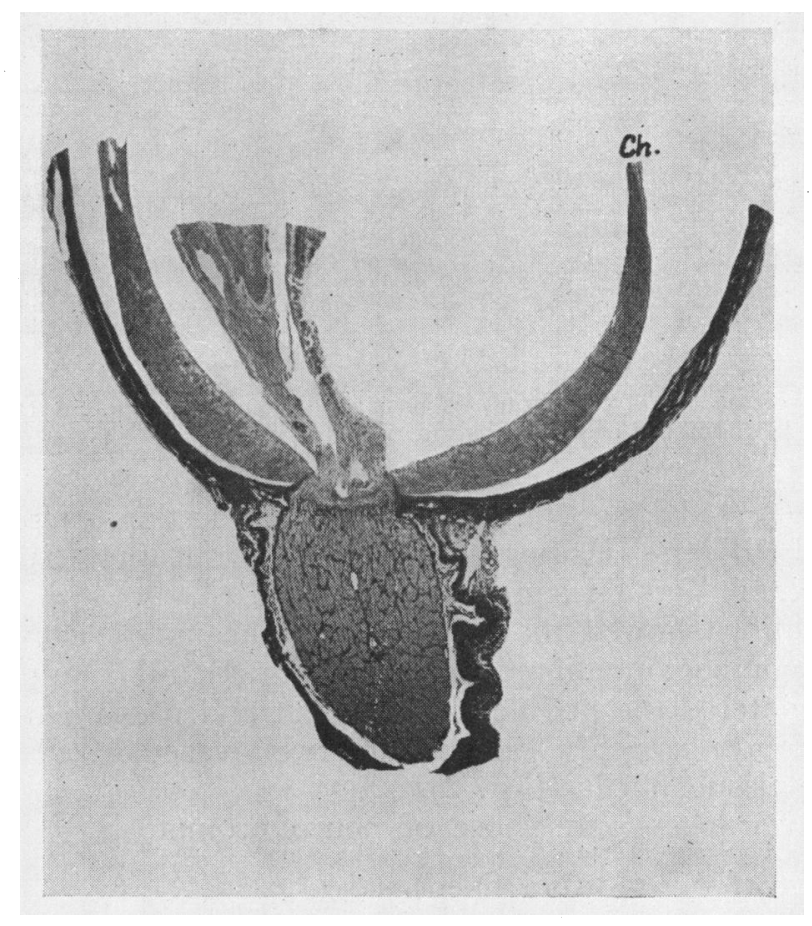

Fig. 3.

Eve specimen. Sagittal section passing through optic nerve head. The apparent retinal thickening is artefact due to wrinkling. Note thickened choroid (ch) Azan. $\times 4.5$.

In the central tumour were well formed adult nerve cells, each with a characteristic nucleus and nucleolus. In none of them could more than two processes be stained so that they appeared to be bipoplar nerve cells (Fig. 5). No mitoses were seen. These nerve cells lay in little groups and between the groups ran whorls and "bundles" which contain myelinated nerves (Fig. 6). 


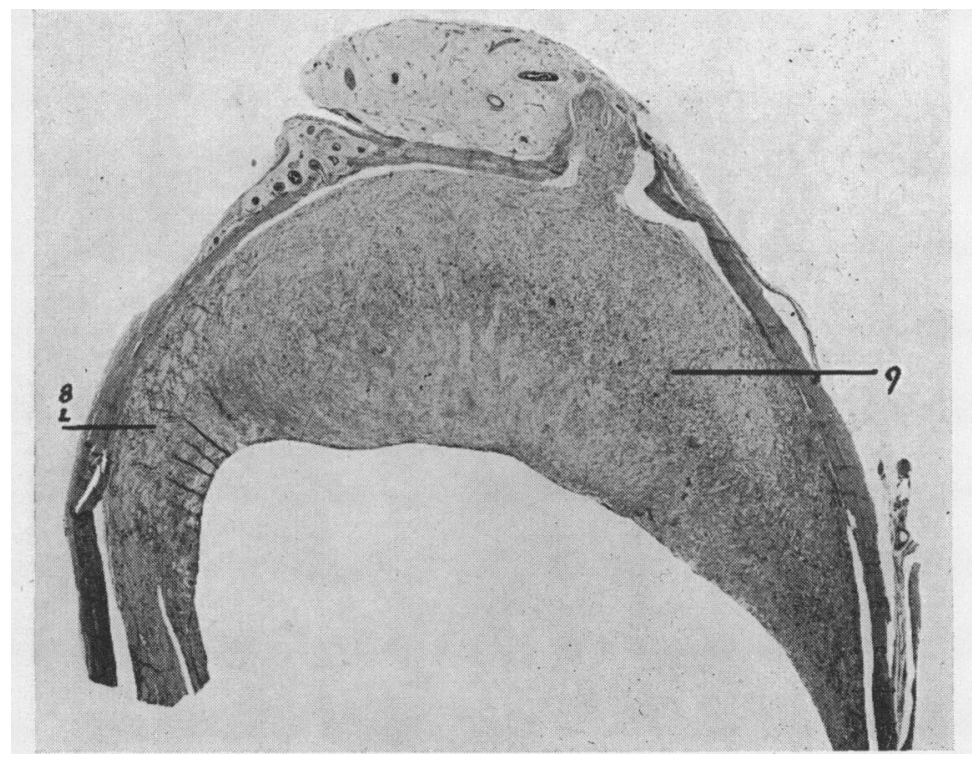

Fig. 4.

Eye specimen. Parasagittal section, through main body of tumour mass. The numbers indicate the approximate areas from which Figs. 6,7 , and 8 were taken. Masson trichome. $\times 6$.

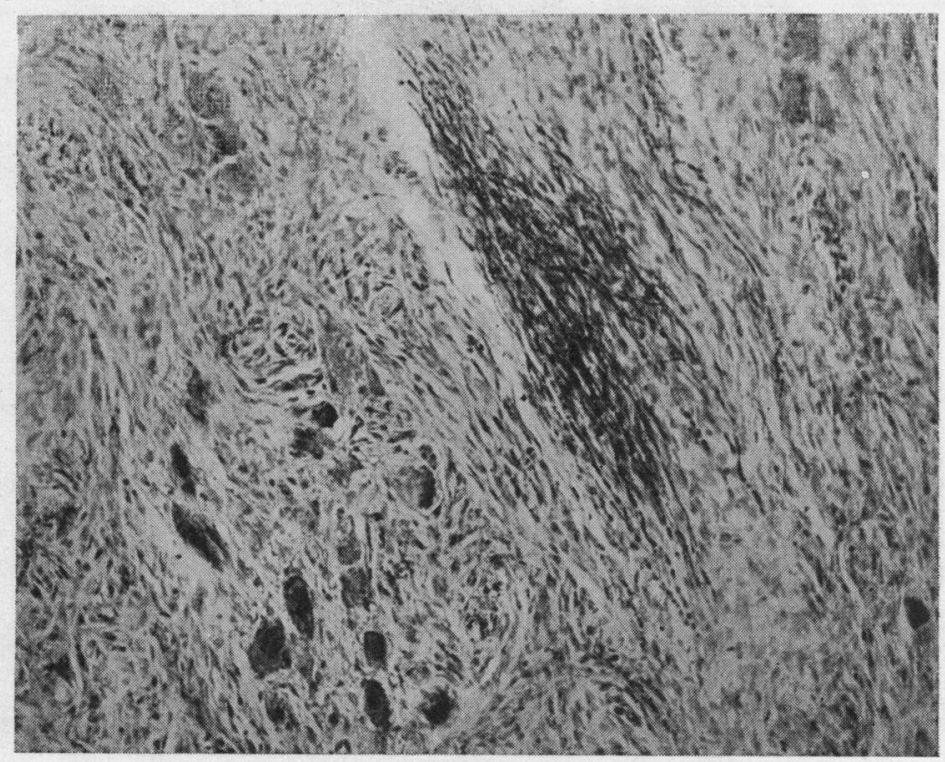

FIG. 5.

Bipolar nerve cell from central portion of tumour. Hortega-neuro fibril stain. $\times 400$. 


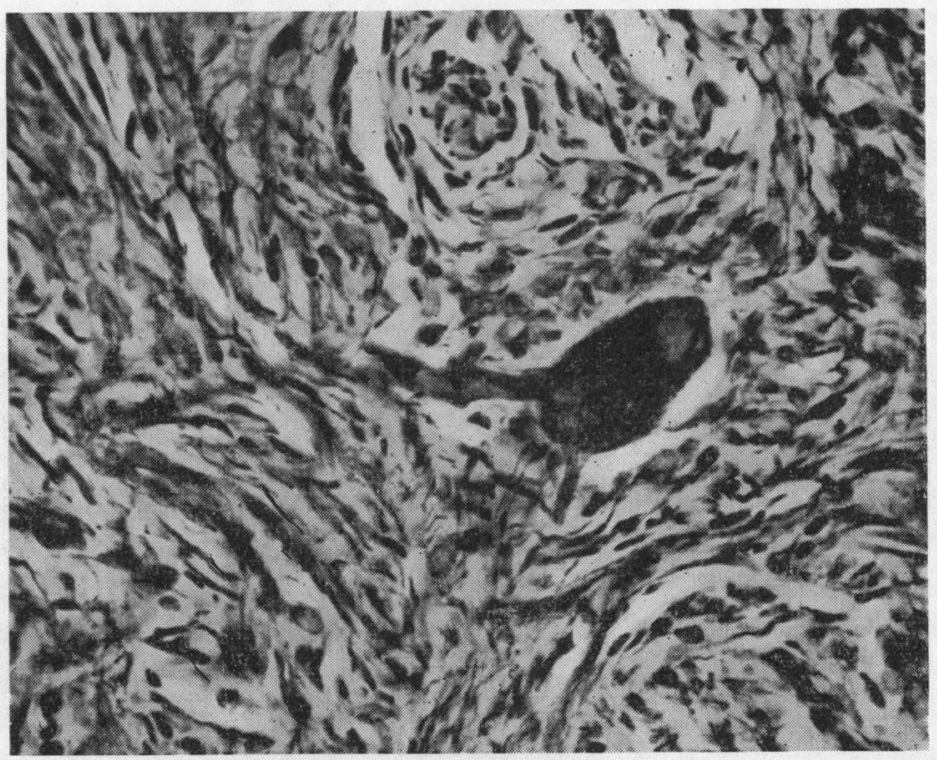

FIG. 6.

Nerve group and "bundle" from central portion of tumour. Spielmeyer myelin sheath stain. $\times 145$.

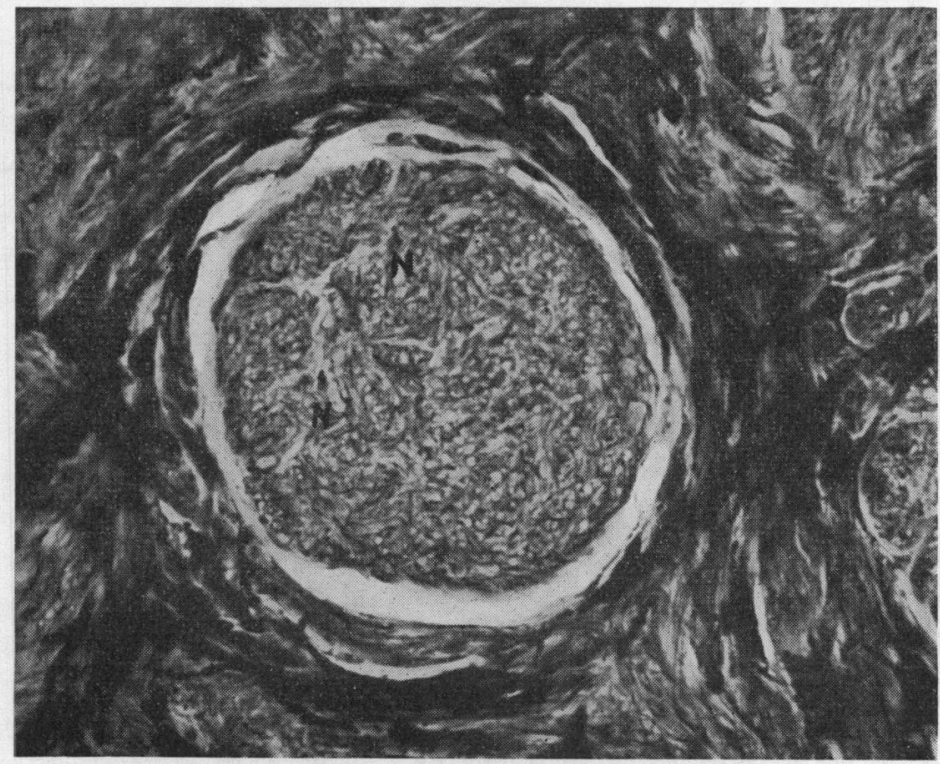

FIG. 7.

Ovoid body from lateral portion of tumour, with contained neurofibrils (N). Hortega neurofibril stain. $\times 300$. 
The number of myelin sheaths in each " bundle" varied and the specimen illustrated is one in which it was greatest. These " bundles," which stained very poorly with haematein eosin, were composed of a fine branching nucleated network of fibres, some of which stained for collagen (green with Masson, blue with Azan) and some for nervous elements (purplish with Masson, red with

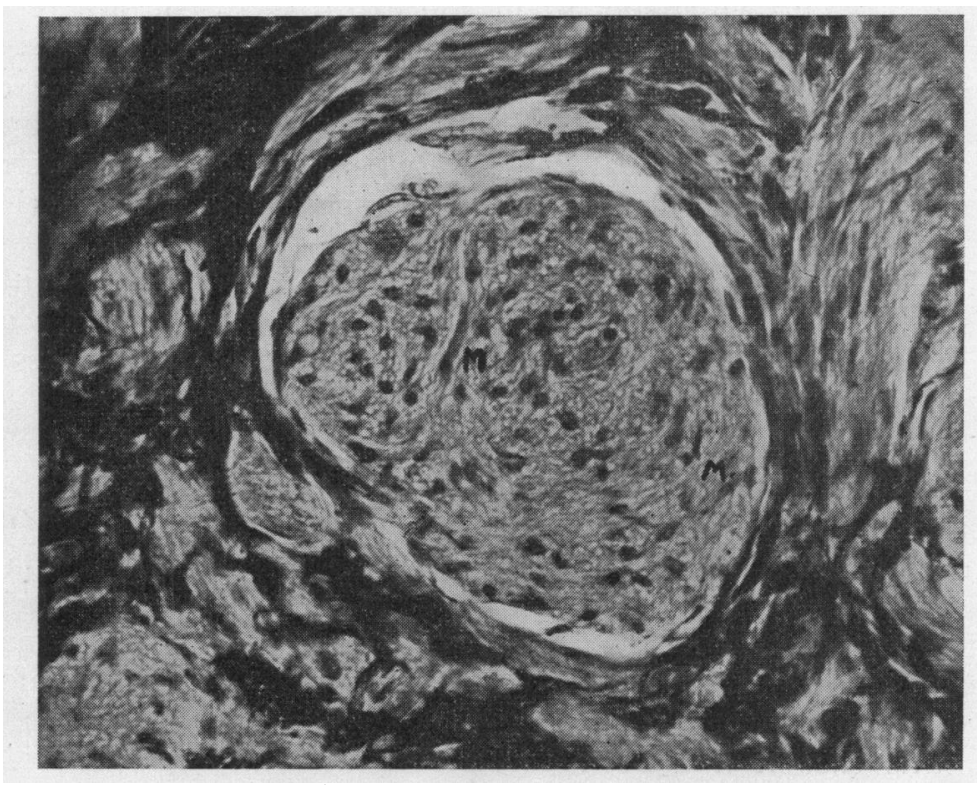

Fig. 8.

Ovoid body from lateral portion of tumour with contained myelin sheaths (M). Note branched melanophores in surrounding stroma. Spielmeyer myelin sheath stain. $\times 300$.

Azan). The nuclei, which were small and non-specific, varied in shape from long and slender to short and ovoid.

Both nerve cell groups and " bundles" were supported by a stroma of young connective tissue.

Irregularly shaped branching melanophores were present in this portion of the choroid but only in its more superficial and deepest paris where the nerve cells were fewest.

At its ill-defined margins, the pale central thickening blended with the diffuse choroidal thickening. This diffuse thickening contained the same elements, except that nerve cells were infrequent. It was composed chiefly of " bundles," continuous with the "bundles" of the central tumour, lying in a scanty fibrous stroma which was diffusely infiltrated by branched melanophores (Fig. 8). 
These " bundles" had the same histological character as those of the central tumour. Here an increasing number had been cut transversely and then they showed a nucleated fibrillar syncytium within which could be demonstrated both neurofibrils (Fig. 7) and myelin sheaths (Fig. 8).

The tumour was only moderately vascular, the vessels being well formed and healthy.

The swelling which lay upon the extra-ocular surface of the sclera was connected with the main tumour through an aperture in the choroid. The extra-ocular swelling appeared to be due to a herniation of the " bundle " portion of the choroidal enlargement through the sclera, at the point where it is normally pierced by the posterior ciliary arteries and the short ciliary nerves (Fig. 4).

The long ciliary nerves, which could be seen running within the substance of the choroid, did not show any abnormality and they were useful as a comparison of the staining qualities of normal nerves.

\section{Comment}

Knight (1925) and Dvorak Theobald (1937) have stated that the choroid normally contains a rich plexus of both medullated and non-medullated nerves, which is derived chiefly from branches of the short ciliary nerves; and that ganglion cells are normally found in the choroid, in relation to the plexus and singly along the vessels.

In this case it had been possible to demonstrate a choroidal enlargement which contained both medullated nerve fibres and nerve cells. It was doubtful if the nerve fibres were increased in number but there was no doubt that there was an increase in their supporting tissues. This increase took the form of a perineural meshwork whose fibres stained specifically both with collagen stains and with stains for myelin sheaths and Schwann cells. Not only was the supporting tissue overgrowth present in the choroid but it was also present in one area in the extrascleral and intrascleral course of the short ciliary nerves.

The histological picture was therefore one of diffuse neurofibromatosis in the distribution of the short ciliary nerves, and it thus fits into the general clinical picture of neurofibromatosis.

The ganglion cells in the tumour were increased in number in the central pale swelling. At first sight the appearances were thought to be those of a ganglioneuroma but Penfield (1932) has commented on the occasional presence of well formed ganglion cells in neurofibromas and, whilst agreeing that it is difficult to guess their origin, thinks that they may be the result of embryonic rests. 


\section{Discussion}

In this case there were the café-au-lait pigmentation, the peripheral nerve nodules and eyelid swellings of neurofibromatosis together with a neurofibroma of the short ciliary nerves.

Similar choroidal tumours, though rare, have been described before. They may occur alone (Freeman, 1934, Meeker, 1936) or may be associated with other neurofibromatous and allied lesions (Snell and Collins, 1903, Collins and Batten, 1905, Wheeler, 1936). These are usually associated with buphthalmos (Knight, 1925, Wheeler, 1936, Davis, 1939) but there may not be this association (Freeman, 1934, Meeker, 1936).

Davis (1939) has recently described a similar case to ours. He has described it so fully that one would hesitate further to burden the literature, were it not that we have been fortunate enough in our sections to demonstrate certain nervous elements, which have not previously been shown and by this demonstration have been able to suggest an explanation for certain previously confusing histological features.

In all cases similar to ours the authors have described and sometimes illustrated ovoid or round bodies, occurring chiefly at the periphery of the tumour, near the equator. Round or ovoid bodies were seen here, in this case (Figs. 7 and 8).

There have been, however, other types of ovoid bodies and they may be classified as :

1. The type likened by Collins (1905) to nerve end organs, by Knight (1925) to hyalinized connective tissue and by Reese (Wheeler, 1936) to Meissnerian corpuscles.

2. The intermediate type seen by Davis (1939) showing definite lamination and with a suggestion of pallisading of the nuclei at each end.

3. The type, the only type seen here, identical with that illustrated by Davis (1939) which he considered to be thickened, nonmyelinated nerves.

We were fortunate enough in our case to be able to demonstrate myelinated nerve fibres within the substance of the " round or ovoid bodies" type 3 (Figs. $\gamma$ and 8 ) and there was little doubt that these ovoid bodies were the result of transverse section of the neurofibromatous bundles which formed the main mass of the tumour.

Masson (1932) who considered single and multiple neurinomata as allied conditions, has shown that, in neurinomata, pallisading may or may not be present and that in the initial stages of pallisade formation there are produced structures which on section resemble Meissnerian corpuscles. 
It is a debatable question whether the underlying pathological basis of localised neurinomata and of diffuse neurofibromatosis is the same. There are many similarities and in view of the above findings of Masson one may suggest that the type 1 and 2 ovoid bodies were the appearances produced by transverse section of early pallisade formation in neurofibromatous bundles.

If this view be accepted then the mystery of the ovoid bodies, of whatever type, is cleared up and they are a normal constituent of the plexiform neurofibromatoses of the short ciliary nerves and the whole but one of the protean manifestations of Von Recklinghausen's disease.

A case of Von Recklinghausen's disease has been described with diffuse neurofibromatosis in the course of the short ciliary nerves.

The histological appearances were similar to previous cases in the literature, including the presence of " ovoid or round bodies."

It has been possible to demonstrate nerve fibres in the " ovoid bodies" and it is suggested that these ovoid bodies are a normal constituent of a diffuse neurofibromatosis.

Our acknowledgements are due to Professor J. D. Wardale for helpful advice and interest in the case and to $\mathrm{Mr}$. J. C. Sommerville for the histological specimens and to $\mathrm{Mr}$. T. Dodds for the photographs other than the snapshots of the patient.

\section{REFERENCES}

Collins, E. T. and Batren, R. D.-Neurofibroma of the eyeball and its appendages. Trans. Ophthal. Soc. U.K., Vol. XXV, p. 248, 1905.

Davis, F. A.-Plexiform neurofibromatosis (Recklinghausen's disease) of orbit and the globe. Arch. of .Ophthal., Vol. XXII, p. 760, 1939.

Freeman, D.-Neurofibroma of the choroid. Arch. of Ophthal., Vol. XI, p. 64, 1937.

KNIGHT, M. S.-A critical survey of neoplasms of the choroid. Amer. Jl. Ophthal., Vol. VIII, p. 791, 1925.

Masson, P.-Experimental and spontaneous Schwannomas (peripheral gliomas). Amer. Jl. Path., Vol. VIII, p. 367, 1932.

MEEKER, L. H - Plexiform neuroma of the choroid in a non-buphthalmic eye. Arch. of Ophthal., Vol. XVI, p. 152, 1936.

PEnfield, W.-Department of Neurosurgery, McGill University, Montreal. Reprint No. 15. Supplement to Chapter, p. 325, 1932.

SNEll, S. and Collins, E. T.-Plexiform neuroma of the temporal region, orbit, eyelid and eyeball. Notes on three cases. Trans. Ophthal. Soc. U.K., Vol. XXIII, p. 157, 1903.

TheоваLD, G. D.-Neurogenic origin of choroidal sarcoma. Arch. of Ophthal., Vol. XVIII, p. 971, 1937.

WheELER, J. M.-Plexiform neurofibromatosis (Von Recklinghausen's disease) involving the choroid, ciliary body and other structures. Trans. Amer. Ophthal. Soc.. Vol. XXXIV, p. 151, 1936. 